\title{
Trafficking Trends, Formal Law Enforcement Cooperation, and Future Perspectives: The Cases of Belarus and Ukraine
}

\author{
Fredric Larsson *
}

\section{Introduction}

Belarus and Ukraine are two countries heavily affected by the traffic in human beings, particularly in women and children for purposes of sexual exploitation. At the same time, these countries have been at the forefront of the fight against this crime, and have made progress in developing strategies and taking political action to combat this crime. Both countries have distinct laws against human trafficking and specialized law enforcement units to address the problem, as well as progressively greater numbers of criminal cases filed and traffickers convicted.

Yet law enforcement agencies in these two countries are still hampered in their efforts by numerous and varied obstacles stemming from their specific national contexts, as well as by shared problems, including a lack of adequate financial resources allocated to counter-trafficking efforts, legislative difficulties created by ambiguous provisions within current laws, limited national inter-agency cooperation, and a severe lack of responsiveness on the part of international law enforcement agencies in countries that are destinations for the victims of human trafficking. The latter issue often has its foundation in the fact that many of the home nations of victims of human trafficking lack certain law enforcement capacities and are still working on developing their own mechanisms of response to international law enforcement agencies. But it is equally due to the persistence of outdated and overly bureaucratic systems for the formal communication of operational and evidentiary information in the international law enforcement community. This severely handicaps the law enforcement response, and lessens the possibility of effective investigations and prosecutions across borders, which further frustrates and demoralizes those in the law enforcement community who are seeking to combat human trafficking.

This essay will examine the specific issue of the effectiveness of formal law enforcement cooperation and its possible relation to current conditions and trends in human trafficking, in particular related to the formal exchange of operational and evidentiary information. This is recognized as a major problem and a constant point of frustration for law enforcement agencies in countries of origin, and one that is frequently raised by law enforcement representatives in various forums. However, little has been done to address this widely recognized problem, in particular with regard to the documentation and analysis of formal law enforcement cooperation. It is not the intention of this paper to provide any comprehensive overview of human trafficking as such, nor the law enforcement response to it in these two countries.

\footnotetext{
Fredric Larsson is the International Organization for Migration's Regional Counter-trafficking Coordinator for Belarus, Moldova and Ukraine. Opinions expressed in this article are those of the author and do not necessarily reflect the views of IOM.
} 
It is my self-evident assumption that effective action against human trafficking and transnational crime requires that national measures be coordinated and combined with international measures, and that avenues should be promoted and enhanced that will encourage dialogue and formal exchange between officials of countries of origin and destination and will facilitate the sharing of operational and evidentiary information. A direct positive correlation between effective law enforcement activity and cooperation and a decrease in trafficking must be assumed. Similarly, inactivity and lack of international cooperation will only continue to provide for an environment conducive for the criminal activities related to human trafficking to continue, diversify, and expand. Finally, it is the ambition of this paper to provide recommendations for actions intended to enhance and stimulate a law enforcement response and to promote cooperation in filling currently identified gaps and needs, with the hope that this may contribute to the evolution of current efforts.

\section{Methodology}

This essay will look at quantitative information derived from the International Organization for Migration (IOM) caseloads regarding assisted victims of trafficking, countries of destination, and formal law enforcement cooperation, with particular attention paid to mutual legal assistance requests dispatched from Belarus and Ukraine to countries of destination. Furthermore, it draws conclusions from the caseload of victims of trafficking that have been provided with direct assistance by IOM in the two countries, in total some 2600 individuals. Although no valid estimates can be made as to the actual numbers of people being trafficked to different countries, the caseload is sufficient to make valid estimates with regard to specific trafficking trends.

Furthermore, this article uses available statistical data as received from the Ministries of Internal Affairs in Belarus ${ }^{1}$ and Ukraine ${ }^{2}$ concerning formalized international law enforcement cooperation, in particular requests for mutual legal assistance. The data related to the Belarus situation is particularly comprehensive and detailed.

Two types of formal law enforcement communication will be examined:

1. Mutual legal assistance (MLA) requests are requests for official information, in accordance with bilateral/multilateral agreements or international regimes governing such processes, and may be sent through the General Prosecutors Office (GPO), Ministry of Justice, etc., depending on the specific country in question, and usually through the diplomatic post.

2. Information requests are requests for basic information related to specific criminal cases-i.e., information related to bank accounts or individual suspects. They are usually sent through Interpol. (Data regarding information requests was not available for Ukraine.)

1 Provided by the Directorate on Investigation of Crimes against Human Beings of the Main Directorate for Preliminary Investigation.

2 Provided by the Main Investigation Department. 
The paper specifically examines the situation related to the six main destination countries for victims of trafficking from Belarus and Ukraine respectively.

This essay had its genesis as a response to the problems regarding practical law enforcement cooperation across borders that were identified by law enforcement practitioners at the Minsk, Kiev, and Chisinau conferences on International Perspectives on Law Enforcement Cooperation in Combating Trafficking in Human Beings. ${ }^{3}$ In particular, it draws on the specific recommendations for international operational and judicial cooperation derived from the discussions at these conferences, as well as numerous practical and qualitative accounts of difficulties that law enforcement officials in these two countries have confronted.

\section{Background}

Since 2000, the International Organization for Migration has provided direct assistance - such as aid with medical, psychological, housing, family and legal issues - to more than 2600 beneficiaries in Belarus and Ukraine. The number of assisted victims of trafficking has increased progressively over the last couple of years. Nonetheless, it is important to note that this increase should not necessarily be seen as evidence of an actual increase in trafficking from these countries, but rather as a result of greater capacity and scope of national referral systems.

\section{The Republic of Belarus}

In the Republic of Belarus, IOM has provided direct assistance to over 500 beneficiaries since 2003, who had been trafficked to twenty-seven different countries. Nonetheless, 49 percent of the individuals had been trafficked to only two countries, Russia and Poland, and 77 percent to the six main destination countries: Russia, Poland, Turkey, Germany, Cyprus, and the United Arab Emirates. 11.5 percent of all victims assisted in 2004-2005 were men. The average age of those assisted was almost twenty-five years of age. 23 percent of the beneficiaries assisted had been trafficked for the purpose of non-sexual forms of exploitation, primarily labor. ${ }^{4}$

Belarus dispatched requests for information to various international law enforcement counterparts in 143 cases related to trafficking in human beings between 1 January 2001 and 8 June 2005. These 143 cases can be divided into information requests (75 cases) and formal mutual legal assistance requests ( 68 cases). They are broken down by country in the table below.

Only 32 percent of the MLA requests related to trafficking in human beings dispatched from Belarus were responded to within a period of three months. ${ }^{5}$ It is noteworthy that less than 24 percent of the requests dispatched to the countries of the European Union had been responded to within a period of three months. ${ }^{6}$ Twenty-four requests

\footnotetext{
3 The conferences were held in Minsk (May 2003), Kiev (May 2004), and Chisinau (May 2005).

4 2004-2005 IOM caseload.

5 Excluding request dispatched in May/June.

6 Excluding request dispatched in May/June.
} 


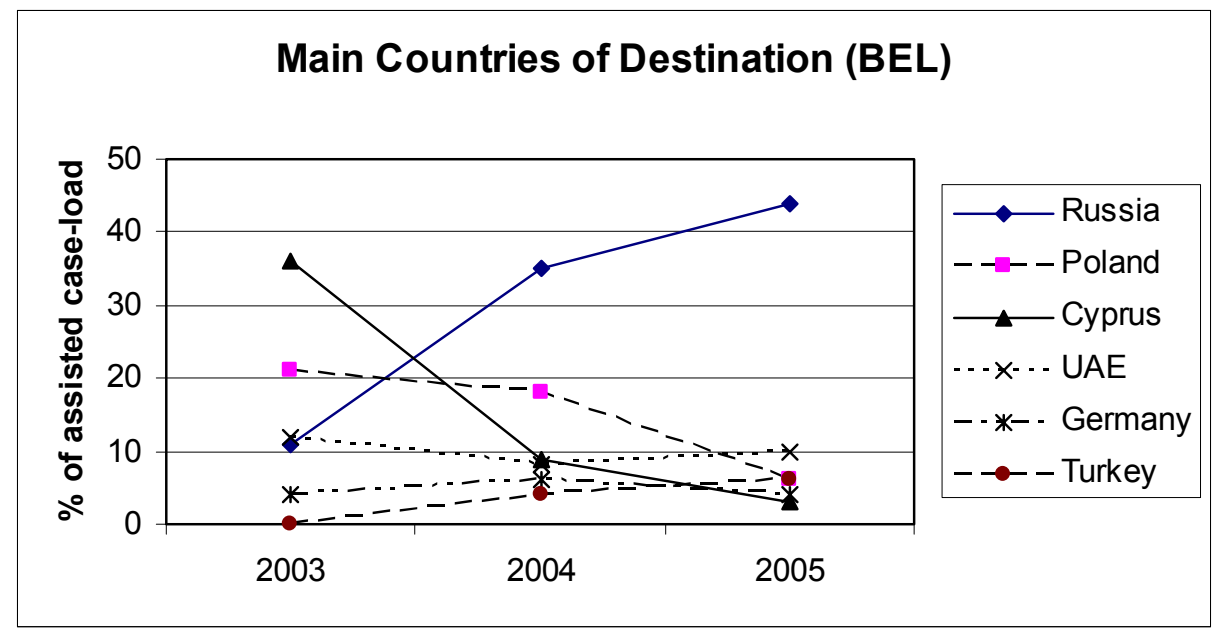

Figure 1: Main Countries of Destination of Victims of Human Trafficking from Belarus

Table 1: Information Requests from Belarus, 2001-2005

\begin{tabular}{lcccc}
\hline \multicolumn{1}{c}{ Type } & $\begin{array}{c}\text { Total } \\
\text { dispatched }\end{array}$ & $\begin{array}{c}\text { Response re- } \\
\text { ceived within } \\
\text { three months }\end{array}$ & $\begin{array}{c}\text { Response not re- } \\
\text { ceived within a } \\
\text { period of three } \\
\text { months/or request } \\
\text { not executed }\end{array}$ & $\begin{array}{c}\text { Response not } \\
\text { received at the } \\
\text { moment of } \\
\text { handling the } \\
\text { case in court }\end{array}$ \\
\hline $\begin{array}{l}\text { Mutual Legal } \\
\text { Assistance request }\end{array}$ & $\mathbf{6 8}$ & $\mathbf{2 0}$ & $\mathbf{4 2}(+\mathbf{6})^{7}$ & $\mathbf{1 3}$ \\
- EU country & 27 & 5 & $21(+1)^{8}$ & 5 \\
- Poland & 8 & 0 & 8 & 4 \\
- Germany & 5 & 3 & 2 & 0 \\
- - Lithuania & 3 & 0 & 3 & 1 \\
- Russia & 20 & 8 & $7(+5)^{9}$ & 3 \\
- Other & 21 & 7 & 14 & 5 \\
Information request & $\mathbf{7 5}$ & $\mathbf{4 9}$ & $\mathbf{1 9}(+\mathbf{7})$ & $\mathbf{1 5}$ \\
\hline
\end{tabular}

Six requests dispatched in May/June.

One request dispatched in May/June.

9 Five requests dispatched in May/June.

${ }^{10}$ Seven requests dispatched in May/June. 
were dispatched to various CIS countries; ${ }^{11} 54$ percent were responded to within three months. ${ }^{12}$ Forty-one MLA requests were sent to the six major destination countries. 64 percent of the requests dispatched to these six countries were not executed within a period of three months. ${ }^{13}$

The authorities in Russia, the main destination country for victims of trafficking from Belarus, had executed and responded to eight out of twenty of the dispatched mutual legal assistance requests within a period of three months. ${ }^{14}$ The Russian authorities had executed twelve requests, and three requests were without response at the time that court proceedings were initiated. With respect to the information requests, six out of eight had been responded to within a period of three months. Two of these responses had not been received at the time of the court proceedings.

Eight mutual legal assistance requests were sent to Poland, the second largest destination country. Poland has responded to three of these requests, none within a period of three months. Five requests - or more than 60 percent-had not been executed at all. For four criminal cases, no response had been received when the case was handled in court. An additional two information requests were dispatched, to which the Belarusian authorities received one response within a period of three months.

The Cypriot authorities responded to one of the two MLA requests dispatched, and this within a period of one month. One MLA request was sent to the UAE, and no response had been received when the case was brought to court. An additional five information requests were dispatched; of these, two were executed by the responding party (two of the requests were sent during May/June 2005, shortly before the writing of this essay). ${ }^{15}$

Of the six major destination countries, Germany stands out as the most positive example. German authorities executed and responded to all mutual legal assistance requests within a period of four months, and executed ten out of eleven information requests, nine of them within a period of two months. Only one information request had not been executed when the criminal case was brought to court.

Five MLA requests were sent to Turkey, only one of which was executed within a period of three months. In addition, seven information requests were sent; five of these were executed within one month.

Finally, it should be mentioned that six MLA requests related to trafficking were sent from Belarus to its neighbor Ukraine. Five of these six requests were executed within a period of three months.

\section{Ukraine}

In Ukraine, IOM has provided direct assistance to more than 2100 individuals since the year 2000. These beneficiaries had been trafficked to forty-seven different countries

11 Excluding request dispatched in May/June.

12 Excluding request dispatched in May/June.

13 Excluding request dispatched in May/June.

14 Five requests dispatched in May/June.

15 Two requests dispatched in May/June. 
across the globe, truly reflecting the global nature of this crime. Nonetheless, more than 50 percent of the caseload had been trafficked to only three countries: Turkey, Russia, and Poland and more than 65 percent to these three countries plus Italy, Macedonia, and the Czech Republic.

Turkey has been the main country of destination for human trafficking from Ukraine since the beginning of the comprehensive direct assistance program and the establishment of the national referral system in 2001. Since 2001, there has been a progressive increase in trafficking to Russia and Poland. From representing only 7 percent of the caseload in 2001, trafficking to Russia has quadrupled, and now accounts for more than 27 percent. ${ }^{16}$ Directly related to the increase of trafficking to Russia, there has also been an increase in the numbers of trafficked minors, in particular for the purpose of sexual exploitation. Trafficking to Poland has seen an even more dramatic increase, from 2 percent in 2001 to 18 percent of the overall caseload in 2005 . $^{17}$

The caseload of victims assisted in Ukraine includes 235 individuals - or 11 percent of the total - of other nationalities from different CIS countries, foremost Moldova. Most of these individuals had been trafficked to Turkey and deported to the port of Odessa in Ukraine.

Although the victims are of all ages and from all strata of society, the average age of the female victims assisted is 26.4 years, and many have complete or partial higher education. 14.7 percent of all referrals in 2004 were men. The recorded incidents of trafficking in men were cases of forced labor in different countries, including the Russian Federation, Turkey, the Czech Republic, Portugal, and Spain.

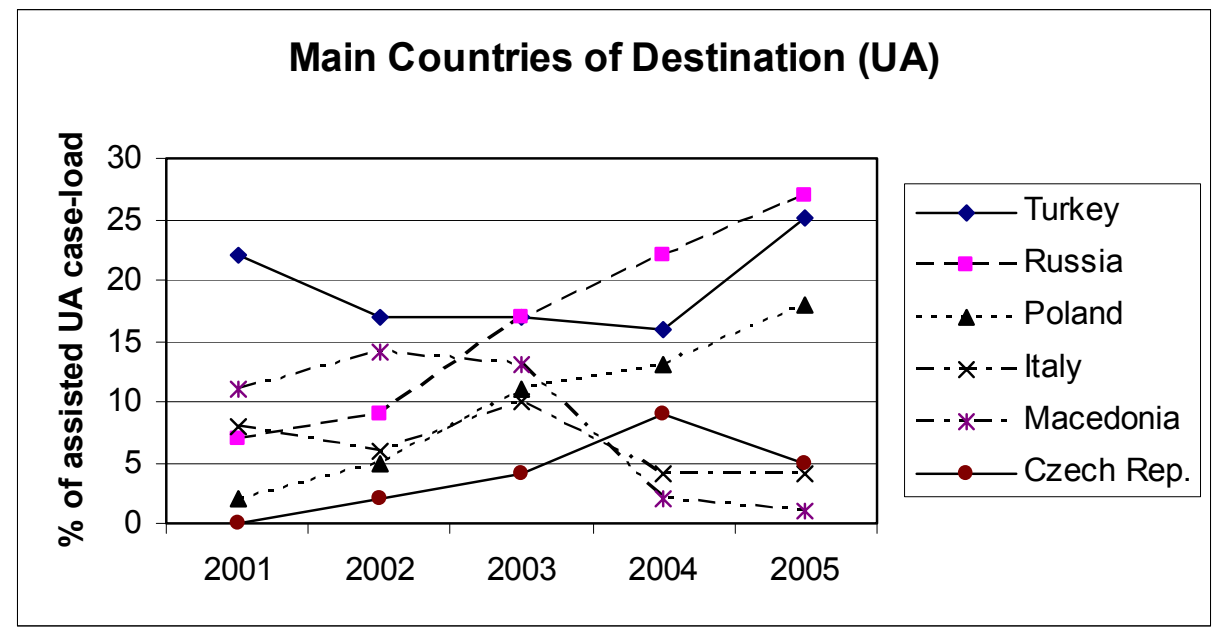

Figure 2: Main Countries of Destination of Victims of Human Trafficking from Ukraine

16 Excluding third-country nationals.

17 Excluding third-country nationals. 
Of the individuals assisted by IOM in Ukraine in 2004-2005, 34 percent had been trafficked for purposes of labor exploitation, an additional 2 percent to serve as beggars, and one case of trafficking for the purpose of criminal activities. ${ }^{18}$ In addition, 6 percent of the caseload had been trafficked for mixed forms of exploitation. The remainder of the victims had been trafficked for purposes of sexual exploitation.

The data available for Ukraine regarding formal law enforcement requests are less comprehensive and detailed than the statistics available for Belarus. Nonetheless, the data available reveal that seventy-eight MLA requests have been sent related to Article 149 of the Ukrainian Criminal Code (which deals with human trafficking) to twenty different countries for the period from January 2002 to June 2005. Only thirty-two requests, or 41 percent, had been executed by the responding party within a period of three months. No information is available related to information requests. Of the twenty-one MLA requests sent to ten different EU countries, 43 percent were executed within three months. Thirty-seven requests were sent to various CIS countries, 65 percent of which were completed within three months. 39 percent of the requests sent to the six main destination countries for persons trafficked from Ukraine-Turkey, Russia, Poland, Italy, Macedonia and the Czech Republic - were not completed (no MLA requests were sent to Poland).

Eleven MLA requests were sent to Turkey, the main destination country. No requests were executed within a period of three months. Eight requests, or 72 percent, had not been completed when the case was brought to trial.

Russia, the second-largest destination country, was the main recipient of MLA requests from Ukraine. Thirty-two requests were sent, and twenty-two of these were completed within a period of two months. Ten requests, or 31 percent, had not been completed.

Surprisingly, no request for MLA had been sent to Poland, the third-largest destination country, and the destination to which trafficking is increasing most rapidly. No explanation was available for this at the time of writing this paper. ${ }^{19}$

Three requests for assistance were sent to Italy, one of which was executed within a period of three months. One request was sent to Macedonia, which has not been executed. Four requests had been sent to the Czech Republic; all of them were completed, and three of them within a period of three months. Finally, two requests had been sent to Belarus. One was completed within one month, while the second was not yet executed at the time of writing.

\section{Conclusion}

As stated above, a direct relationship between effective law enforcement activity and cooperation and the decrease in trafficking must be assumed. Similarly, inactivity and lack of international cooperation will provide for an environment that is more congenial to the criminal activities related to human trafficking, one that is more likely to allow

18 Up to 31 March 2005.

19 There are indications that the statistics received might not be complete in this regard. 
the transnational crime to continue, diversify, and expand. Effective action against trafficking requires that national measures be combined with international measures through the development of adequate cooperation and investigation mechanisms across borders, and that the nature of the law enforcement response in both countries of origin and countries of destination reflect the severity of the crime involved. Currently, there seems to be a gap between political commitments and intentions and actual action, resulting in a response that does not fit the crime. Unfortunately, the current international law enforcement response has shown itself to be impotent in the face of the complex nature of the crime and the new investigative challenges posed by trafficking in human beings, mostly due to a failure to adapt to the new, transnational criminal environment. The weak response in countries of destination as well as origin is often explained by law enforcement agencies as being the product of procedural regulations, linguistic problems, data protection issues, prioritization of crime, and lack of financial resources, as well as corruption and general non-reliability amongst counterparts. Nonetheless, it could be perceived that chalking up difficulties to these more intractable causes has resulted in the consolidation and preservation of current systems of operation, and the denial of actual and chronic systemic problems that could be addressed.

The main conclusion from the data provided and the simple analysis made in this paper clearly shows that current law enforcement cooperation and procedural systems are not working satisfactorily, with very few exceptions. Furthermore, it reveals that measures must be taken if the international response to combating this serious crime and abuse of human rights - one that mostly affects women and children — is to be taken seriously and have any tangible effect.

Bilateral and multilateral agreements directed at facilitating improved law enforcement cooperation are important. Nonetheless, any form of agreement is of limited value if cooperation is not aggressively pursued by law enforcement agencies in countries of both destination and origin.

The data clearly indicate that the presence of administrative, historical, cultural, and linguistic borders seem to be directly related to the effectiveness of cooperation (or lack thereof). Unfortunately, these are the challenges that are faced when investigating trafficking cases, as these "borders" are present in most criminal cases. It is particularly important to recognize that these fictive borders will not disappear. Therefore, even if law enforcement agencies perceive themselves as bound by borders of an administrative, political, or cultural nature, using these international distinctions to justify their own inaction should not be accepted.

A major paradox emerges from the basic analysis conducted in this essay. The same counterparts that now are contributing significant financial support aimed at the eradication of human trafficking in many countries of origin are the same actors who are amongst those that are most lax in their efforts to cooperate on the practical level in countering this transnational crime. This results not only in a political and practical paradox, but also in many-what must be assumed - puzzled taxpayers, who wonder where their taxes are being spent.

A further important conclusion that can be drawn from this paper is that quantitative evidence and verifiable indicators as related to the effectiveness of law enforcement co- 
operation can be gathered. In order to be able to address some of the needs and gaps identified in this paper effectively, and to be able to make a more detailed analysis in the future, such information should be gathered in a regular and structured manner. Only through such measures can greater accountability be placed on law enforcement agencies related to transnational crimes. And it is only this accountability that can ensure that the structures of law enforcements will possess continued relevance and effectiveness in a world of transnational crime, as well as legitimacy in the eyes of their citizens.

At present, few comprehensive overviews are available related to the scope of human trafficking, and there are even fewer means of effectively influencing state responses towards the problem, even if the quantitative information (as presented above) is available. Currently the best - and only - form of accountability and real influence is the U.S. State Department's annual "Trafficking in Persons" report. This report identifies as one of the critical indexes of "serious and sustained efforts to eliminate severe forms of trafficking in persons ... [w] hether the government of the country cooperates with other governments in the investigation and prosecution" of human trafficking. ${ }^{20}$

Furthermore, there seems to be some evidence that shows a direct link between law enforcement inactivity and trends related to human trafficking. Nonetheless, the available information is inconclusive, and should be interpreted carefully, primarily due to the limited data available and the multiple factors influencing this issue.

In conclusion, we must again emphasize that to be able effectively to combat trafficking in human beings, law enforcement agencies need to think beyond national borders and work corporately rather than territorially, seeing this as a challenge and opportunity rather than a barrier. The law enforcement community must aggressively seek cooperation across borders, and should work to reform systems of cooperation that are no longer effective, to combat this modern-day slave trade.

\section{Recommendations}

Below are listed some key recommendations for action that will help improve the international law enforcement response to human trafficking. Governments and other relevant stakeholders should endeavor to:

- Promote relevant organizational changes and more aggressively pursue a policy of joint investigations and cooperation. Just as important, a less defensive approach towards innovative measures must be adopted, in order to increase the effectiveness and relevance of current cooperation mechanisms and structures and help them adapt to the rapid evolution of trafficking and organized crime in the twentyfirst century.

- Take steps to systematically collect comprehensive quantitative and qualitative information related to law enforcement agencies' exchange of operational and evi-

20 Trafficking Victims Protection Act of 2000, Div. A of Pub. L. No. 106-386, § 108, as amended in U.S. Department of State, "Trafficking in Persons Report" (June 2005), 252. 
dentiary information and the results thereof on a national level as well as on an international level (by governments and relevant international bodies responsible for such exchange). In addition, states must be able to validate the effectiveness of current responses and the usefulness of current systems.

- Allocate sufficient human and financial resources to be able to comply and swiftly respond to mutual legal assistance requests related to trafficking in human beings as a matter of priority.

- Establish and enhance vehicles that encourage dialogue between officials of the countries of origin and destination - across administrative, historical, cultural, and linguistic borders - to effectively share intelligence and operational and evidentiary information.

- Effectively reform structures to combat organized crime. Transparency and accountability must be promoted regarding international law enforcement cooperation.

- Encourage language training for law enforcement officers. ${ }^{21}$

- Further increase exchanges of liaison officers. ${ }^{22}$

- Develop "a system of national centralized bodies designated to process mutual legal assistance requests." 23

- Develop "direct secure electronic transmission of mutual legal assistance requests between central authorities." 24

- Provide "a progress report on the execution of the Letter of Request and acknowledgement of receipt within twenty-eight days of receipt within the requested state; a specific deadline for the completion of the request set by the prosecutor, or other relevant party, who prepares the Letter of Request and which reflects the date by which any failure to execute the request would place the prosecution at risk of failure; and specific grounds setting out why the request may be urgent." 25

21 Recommendation No. 6, Minsk Recommendations for International Operational and Judicial Cooperation in Combating Trafficking in Human Beings, International Law Enforcement Conference: "International Perspectives on Law Enforcement Cooperation in Combating Trafficking in Human Beings," Minsk, 16 May 2003.

23 Recommendation No. 34, ibid. 
- Develop and implement "a system of prioritizing Letters of Request ... as a matter of urgency.... Trafficking of human beings should receive high priority status, and the trafficking of children should receive the highest priority of all." ${ }^{26}$

- Further "increase the use of existing liaison networks to facilitate the faster return of evidentiary documents obtained during the execution of Letters of Request."27

- Create mechanisms so that "the conduct of mutual legal assistance provisions should be monitored to ensure compliance with the requirements of legal instruments.... If necessary, a 'blacklist' of those countries that repeatedly fail to execute these requests appropriately could be published by the monitoring mechanism. In addition and where appropriate, administrative sanctions should be applied against those staff members that fail to conduct mutual legal assistance in accordance with the rules.",28

- Facilitate "a comprehensive evidentiary review of problem areas and areas of best practice by each counter-trafficking criminal justice unit (operational units, investigative units, and prosecution units) over the course of the next twelve months, by collecting and analyzing factual data ... in the conduct of international operational and judicial cooperation." 29

\footnotetext{
Recommendation No. 33, ibid.

27 Recommendation No. 36, ibid.

28 Recommendation No. 37, ibid.

29 Recommendation No. 43, ibid.
} 